\title{
COMMON LEOPARD PREYED ON JUNGLE CAT: EVIDENCE FROM THE MID-HILL OF NEPAL
}

\author{
KedAr BARAL ${ }^{1,2}$, BinAYA AdHIKARI ${ }^{3,4}$, ShIVISH BhANDARI ${ }^{5 *}$ \\ ${ }^{1}$ Institute of Natural and Mathematical Sciences, Massey University, New Zealand \\ ${ }^{2}$ Division Forest Office, Kaski, Nepal \\ ${ }^{3}$ Tribhuvan University, Institute of Forestry Pokhara, Kaski, Nepal \\ ${ }^{4}$ Pokhara Zoological Park and Wildlife Rescue Center, Kaski, Nepal \\ ${ }^{5}$ Morgan State University, Baltimore, Maryland 21251, USA \\ *Corresponding author: Shivish Bhandari, email: shbha4@morgan.edu
}

\begin{abstract}
.
Camera traps, an effective measure to monitor wildlife ecology, are used to capture images of wildlife with as little human interference as possible. We installed camera traps in a mid-hill region of Nepal in $1 * 1 \mathrm{~km}$ grids covering 60 $\mathrm{km}^{2}$ areas. Out of 36 pairs of camera traps across the location, a pair of camera traps captured an unusual image of a common leopard (Panthera pardus) preying on a jungle cat (Felis chaus). The incidences of camera traps capturing the hunting behavior of a larger felid species preying on smaller-sized Felidae is quite rare. This study signifies the possibility that the predation within the same family could be attributed to a lack of preferred prey species in the area or modified prey predator interaction in a human-dominated landscape. This finding contributes to better understand of the common leopard ecology by representing their hunting behavior of predating sympatric carnivore species. This type of evidence could contribute towards formulation of conservation actions focused on prey-predator interactions and could specifically signify that conservation of natural prey species, including small carnivores such as jungle cat, could be key to conserve the vulnerable leopards in the area.
\end{abstract}

Key words: common leopard, jungle cat, carnivore, prey, predator, felid, camera-traps

\section{INTRODUCTION}

Carnivores play an important role to sustain and regulate the forest and grassland ecosystem. The impacts of predation activities create a ripple effect that affects the downward trophic levels of the ecosystem (Miller et al. 2001). In general, predators are the animals that naturally prey on the other, therefore, carnivore species can be recognized as predators. The majority of terrestrial carnivores usually feed on several invertebrates, small vertebrates, and large-sized vertebrates (Carbone et al. 1999). The selection of prey is a critical factor in understanding the life history strategies of the species (Miquelle et al. 1996). There are various factors that affect the pattern of prey selection which includes the morphology and requirement of habitat according to the hunting behavior (Husseman et al. 2003; Quinn \& Cresswell 2004).

The hunting behavior of large predators is a highly complex phenomenon and usually needs a detailed study on the association of various dynamic and interacting factors relating to prey vulnerability in order to efficiently predict the scenario (Quinn \& Cresswell 2004). The strategies adopted by predators are shaped by the need to maximize the intake of nutrients while enduring several ecological constraints such as habitat and density of prey (Sunquist \& Sunquist 1989; Adhikari et al. 2022). These strategies may even vary for the same species according to the various scenarios in different geographical distributions (Sunquist \& Sunquist 1989).

Sympatric large carnivore species coexist with the assistance of differences in their niche (Pianka 1974). This coexistence is usually governed by dissimilarity in hunting strategies and by the selection of different sets of prey in accordance with the size (Karanth \& Sunquist 1995; Owen-Smith \& Mills 2008). The quality and quantity of diet determine the survival of any predator and hence carnivores that differ in morphology have evolved themselves to feed on the prey of different types of various sizes (Krebs 1978).

Felidae refers to the family of mammals in the order carnivore. Felidae species displays the most diverse fur pattern among all terrestrial carnivores (Peters 1982) and are characterized by their retractable claws, flexible forelimbs, and muscular slender body. They are predominantly solitary creatures with the strategy of stalking and ambushing their prey for a kill. They are further divided into five subfamilies based on their phenotypic features (Pocock 1917). 


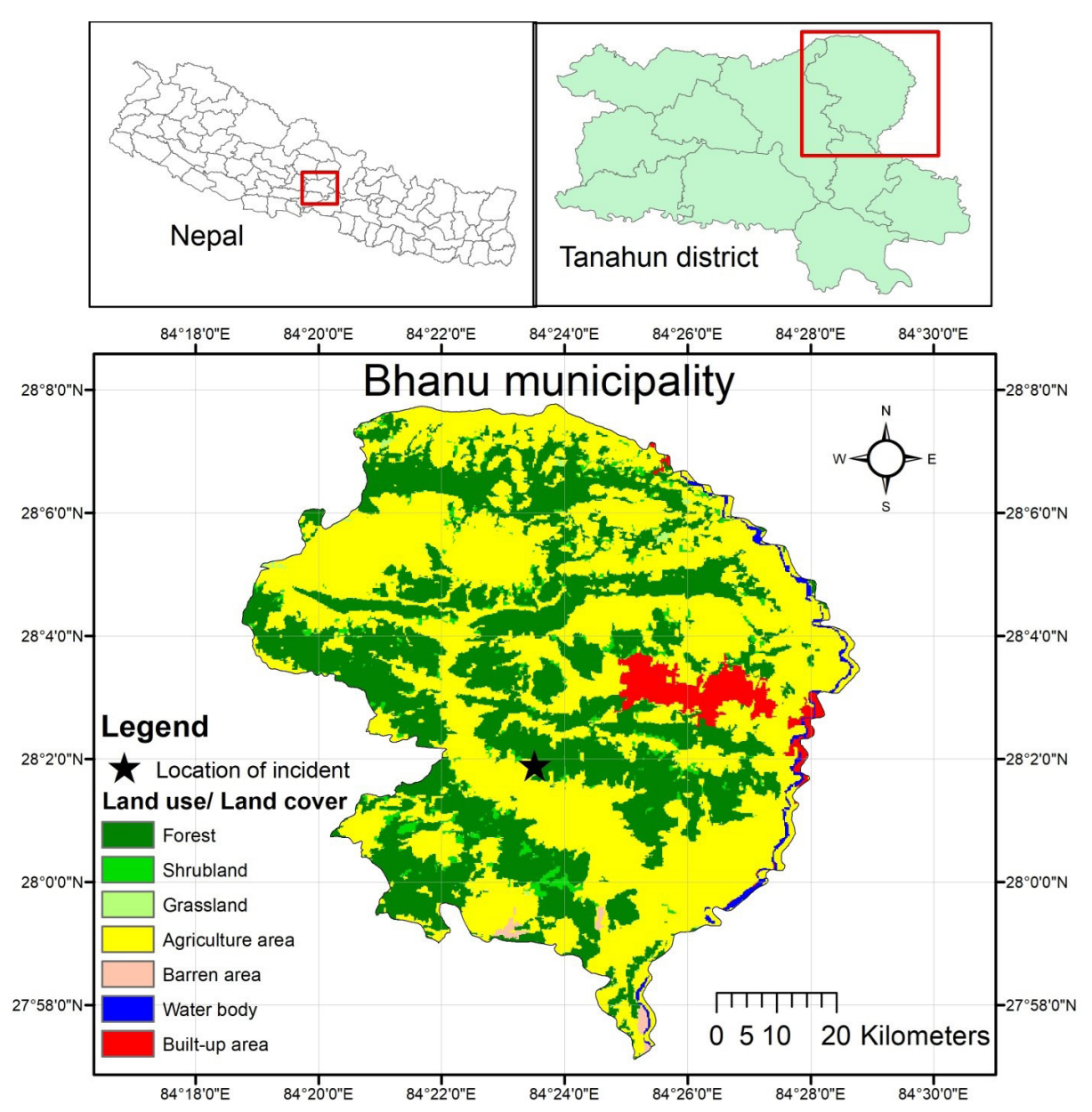

Figure 1: The study site location, Tanahun district of Nepal.

Common leopard (Panthera pardus) descends from Panthera lineage whereas Jungle Cat (Felis chaus) descends from Felis lineage.

Common leopard is categorized as vulnerable in IUCN red list because of the decline of their population due to habitat loss, fragmentation, poaching, and retaliation killing (Stein et al. 2008). It usually occurs in tropical rainforests, temperate forests, and dry deciduous forests and also is known to exist in coniferous forests throughout its range in South Asia (Nowell \& Jackson 1996, Bhandari et al. 2019). The male of this species is known to grow between 60 and $70 \mathrm{~cm}$ at the shoulder, $127 \mathrm{~cm}$ to $142 \mathrm{~cm}$ in length and weigh between 50 and 77 $\mathrm{kg}$, whereas females grow between $57 \mathrm{~cm}$ and 64 $\mathrm{cm}$ at the shoulder, $104 \mathrm{~cm}$ to $117 \mathrm{~cm}$ in length and weigh between 29 and $34 \mathrm{~kg}$ (Pocock 1917). Similarly, the Jungle cat is categorized as the least concern on IUCN red list and is generally threatened due to the destruction of its habitat and anthropogenic conflicts (Gray et al. 2016). The jungle cat is distributed through the Middle East, Indian subcontinent, Southeast Asia, and southern China (Gray et al. 2016). This species approximately measures $36 \mathrm{~cm}$ at the shoulder and is known to weigh 2-16 kilograms on average (Burnie \& Wilson 2001).

Common leopards have one of the most diverse diets among the Felidae family. They are known to feed on a wide range of prey which includes various sized ungulates, birds, small rodents, other small mammals, and livestock (Nowell \& Jackson 1996; Hayward et al. 2006). Though they feed on a variety of prey, common leopards are known to prefer medium-sized prey within the weight range of 10$40 \mathrm{~kg}$ (Hayward et al. 2006; Karanth \& Sunquist 1995). Though the instances of leopard preying upon domestic preys are frequently mentioned in studies (Shehzad et al. 2015; Athreya et al. 2016; Kumbhojkar et al. 2020), there have been only a few studies (Ott et al. 2007; Rostro-Gracia et al. 2018) mentioning the instances of leopards preying on other small carnivores. 


\section{Methods}

An intensive camera trap survey was conducted from November to December 2020 in a mid-hill region of Nepal (Fig 1). The major objective of this study was to estimate the density of common leopards using the spatial capture-recapture technique. A total of 36 grids $(1 \mathrm{~km} * 1 \mathrm{~km})$ were overlaid in an area of approximately 60 square kilometers. A total of 72 cameras (model: StalthCAM) were equipped for 15 days with a total combined trap effort of 1080 trap nights. A camera station was established at each grid and consisted of two cameras facing each other at a distance of 5-8 meters in length. The camera traps were installed at trails and junctions of each grid after identifying possible common leopard activities through the help of a sign survey. Camera traps were installed at the height of approximately $45 \mathrm{~cm}$ from the ground level attached to trees or poles.

\section{Results}

Out of 36 camera trap stations, a series of pictures of a common leopard preying upon a jungle cat in one station (Lat 28.0325, Lon 84.3886, Alt $511 \mathrm{~m}$.) was recorded. The photographs constituted the images of the predator grabbing the prey with the grip of its jaw (Fig 2). The series of photographs depicted that the common leopard arrived at the camera station with a jungle cat in its grip at 3:51 am and stayed in that spot for 2 minutes before moving and dragging the prey towards an upper trail at 3:53 am. The event occurred in an area dominated by Sal (Shorea robusta) trees which was close $(<100 \mathrm{~m})$ to the human settlement.

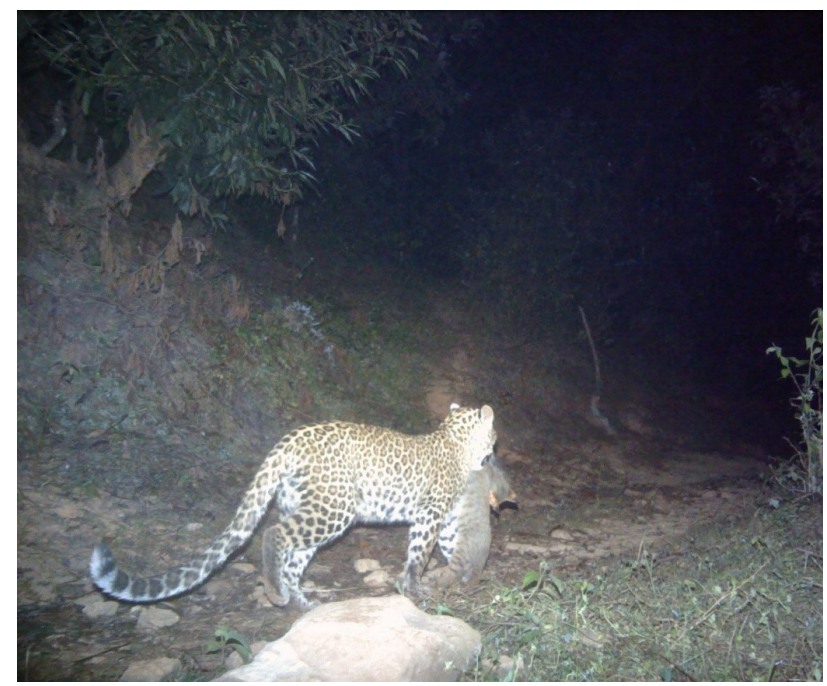

Figure 2: The Common leopard preyed on Jungle cat, a camera trap image

\section{Discussion}

Common leopard is one of the largest predators in the tropical forests in the mid-hill regions of Nepal; however, it has comparatively low competition for prey selection in mid-hills because of the limited distribution of other big cats such as tiger (Panthera tigris), which is mostly limited on lowlands and snow leopard (Panthera uncia), which is limited in highlands (DNPWC 2017; Adhikari et al. 2022). This signifies that the common leopard is the apex predator in the mid-hills and generally exists alongside only smaller felids such as Jungle cat, leopard cat (Prionailurus bengalensis) clouded leopard (Neofelis nebulosa) and other smaller carnivores.

Based on the photographic evidence, our study reported jungle cat as a prey for the leopard. However, jungle cats aren't usually the preferred preys since species like barking deer (Muntjak vaginalis) or wild boar (Sus scrofa) are usually associated as leopard's primary preys in the mid-hills regions (Aryal \& Kreigenhofer, 2009). Decreasing abundance of leopard's preferred prey species such as barking deer and wild boar in recent years have been reported in the area (DFO 2021). Similarly, a camera trap study (Sharma et al., 2021) conducted in the Bhanu municipality of Tanahun district reported high relative abundance index of jungle cat and other sympatric small/medium bodied carnivores, whereas, low relative abundancewas attributed to species like barking deer. These studies, together with our photographic evidence, could signify low abundance of leopard's preferred prey and high abundance of small carnivores in the study area. This scenario could have potentially forced leopard to survive on low preferred and high abundant preys such as jungle cat.

Carnivores aim to minimize the time and effort used to find prey because it takes a substantial amount of energy for a kill. There is an expense of large energy to pursue and subdue a big prey which creates a 2-fold step increase in the expenditure of energy (Carbone et al. 1999). In order to minimize the effort for a kill, leopards could have been wandering around human settlements because livestock is usually the easier prey compared to the wild prey. A small carnivore wandering around the human settlement in search of its prey could have been the easier target for the common leopard to ambush upon compared to the heavily guarded livestock such as goats, poultry, and dogs.

The trail where the camera was stationed, represented a junction foot trail that led from the forest 
area towards a village settlement. The trail was often found to be utilized by the local herders to move their livestock from the village towards the forest for the purpose of grazing. The nearest house was less than 50 meters from the camera station whereas the nearest water source was approximately 30 meters away. There was frequent activity of jungle cat and leopard in that particular trail even several days before this unusual incidentwhich signifies repeated use of thistrail by both species. Trail intersections serving as common boundaries between territories are known to be frequently utilized by species such as leopards (Wang \& MacDonald, 2009). The incident occurred very close to a human settlement and the presence of jungle cats in close proximity to the humans could be explained by their preference towards poultry and rats (Rattus rattus) as their prey species (Mukherjee et al.2004; Majumder et al.2011; Bhandari et al. 2017). The presence of crops in agricultural lands attracts rodent species (Rodentia) (Stenseth et al. 2003), favoring frequent activity of jungle cats around the area for the search of prey. Similarly, various studies have mentioned common leopard's adaptation in highly human dominated areas (Athreyaet al.2016; Bhandari et al. 2017; Van Cleave et al. 2018; Bhandari et al. 2019). This shift and the behavioral adaptation are generally associated with lack of prey in the forest, habitat fragmentation, and degradation (Athreya et al., 2013; Athreya et al., 2016; Naha et al., 2020).

Though studies have reported the traces of small carnivores in the diet of leopard (Athreya et al., 2016, Khatoon et al., 2019), photographic evidences of leopard preying on small felid is quite rare event. The probability of the camera trap capturing photographs of two felids at the same time, of such an unusual incident of felid preying upon other felid is quite low.

In conclusion, this event depicts the unusual prey selection of common leopard which could be attributed to decreasing abundance of preferred preys. This result also implies that conservation endeavors for the vulnerable common leopard should also place equal importance in meticulous studies on prey-predator interaction and conserve small carnivores for sustained conservation of this vulnerable felid.

\section{ACKNOWLEDGMENTS}

We thank the Divisional Forest Office Tanahun for the logistic support. Our thanks go to local people and community forest communities at Bhanu $\mathrm{Mu}-$ nicipality, Tanahun, Nepal for the field support. We thank Dr. HS Baral for the camera trap support.

\section{REFERENCES}

Adhikari, B., Baral, K., Bhandari, S., Szydlowski, M., Kunwar, R. M., Panthi, S., Neupane, B., \& Koirala, R. K. (2022). Potential risk zone for anthropogenic mortality of carnivores in Gandaki Province, Nepal. Ecology and Evolution, 12, e8491.

Aryal, A., \& Kreigenhofer, B. (2009). Summer diet composition of the common leopard Panthera pardus (Carnivora: Felidae) in Nepal. Journal of Threatened Taxa, 562-566.

Athreya, V., Odden, M., Linnell, J. D., Krishnaswamy, J., \& Karanth, U. (2013). Big cats in our backyards: persistence of large carnivores in a human dominated landscape in India. PloS one, 8(3), e57872.

Athreya, V., Odden, M., Linnell, J. D., Krishnaswamy, J., \& Karanth, K. U. (2016). A cat among the dogs: leopard Pantherapardus diet in a human-dominated landscape in western Maharashtra, India. Oryx, 50(1), 156-162.

Bhandari, S., Chalise, M. K., \& Pokharel, C. P. (2017). Diet of Bengal Tigers (Panthera tigris tigris) in Chitwan National Park, Nepal. European Journal of Ecology, 3(1), 80-84.

Bhandari, S., Mawhinney, B.A., Johnson, D., Bhusal, D.R., Youlatos, D. (2019). Coexistence of humans and leopards in Shivapuri Nagarjun National Park, Nepal. Russian Journal of Ecology 50(6), 590-592.

Burnie, D., Wilson, D.E., eds. (2001). Animal (1st American ed.). New York: Dorling Kindersley. ISBN 978- 07894-7764-4.

Carbone, C., Mace, G., Roberts, S. et al. (1999). Energetic constraints on the diet of terrestrial carnivores . Nature 402, 286-288.

DFO. (2021). District Forest Office Tanahun, annual report fiscal year 2076-2077, Tanahun, Nepal.

DNPWC. (2017). Snow leopard conservation action plan for Nepal (2017-2021). Department of National park and Wildlife Conservation (DNPWC), Government of Nepal, Kathmandu, Nepal.

Gray, T. N. E., Timmins, R. J., Jathana, D., Duckworth, J. W., Baral, H., \& Mukherjee, S. (2016). Felis chaus. The IUCN Red List of Threatened Species 2016: e. T8540A50651463.

Hayward, M. W., Henschel, P., O’Brien, J., Hofmeyr, M., Balme, G., \&Kerley, G. I. (2006). Prey preferences of the leopard (Panthera pardus). Journal of Zoology, 270(2), 298-313.

Husseman, J. S., Murray, D. L., Power, G., Mack, C., Wenger, C. R., \& Quigley, H. (2003). Assessing 
differential prey selection patterns between two sympatric large carnivores. Oikos, 101(3), 591601.

Karanth, K. U., \& Sunquist, M. E. (1995). Prey selection by tiger, leopard and dhole in tropical forests. Journal of Animal Ecology, 439-450.

Khatoon, R., Anwar, M., Habiba, U., Mustafa, N., Khalil, S., Eggert, L. S., \& Gompper, M. E. (2019). Diet of common leopard and leopard cat in Murree, KotliSattian and Kahuta National Park, Pakistan: contrasting patterns of domestic animal and wild carnivore consumption. Int $\mathrm{J}$ BioSci, 15(1), 321-330.

Krebs, J. R., Kacelnik, A., \& Taylor, P. (1978). Test of optimal sampling by foraging great tits. Nature, 275(5675), 27-31.

Kumbhojkar, S., Yosef, R., Kosicki, J. Z., Kwiatkowska, P. K., \&Tryjanowski, P. (2020). Dependence of the leopard Panthera pardus fusca in Jaipur, India, on domestic animals. Oryx, 1-7.

Majumder, A., Sankar, K., Qureshi, Q., \& Basu, S. (2011). Food habits and temporal activity patterns of the Golden Jackal Canisaureus and the Jungle Cat Felis chaos in Pench Tiger Reserve, Madhya Pradesh. Journal of Threatened Taxa, 2221-2225.

Miller, B., Dugelby, B., Foreman, D., Rio, C.M., Noss, R., Phillips, M.K., Soule, M., Terborgh, J., \&Willcox, L. (2001). The Importance of Large Carnivores to Healthy Ecosystems.

Miquelle, D. G., Smirnov, E. N., Quigley, H. G., Hornocker, M. G., Nikolaev, I. G., \& Matyushkin, E. N. (1996). Food habits of Amur tigers in Sikhote-AlinZapovednik and the Russian Far East, and implications for conservation. Journal of Wildlife Research, 1(2), 138-147.

Mukherjee, S., Goyal, S. P., Johnsingh, A. J. T., \& Pitman, M. L. (2004). The importance of rodents in the diet of jungle cat (Felischaus), caracal (Caracal caracal) and golden jackal (Canisaureus) in Sariska Tiger Reserve, Rajasthan, India. Journal of Zoology, 262(4), 405-411.

Naha, D., Dash, S. K., Chettri, A., Chaudhary, P., Sonker, G., Heurich, M., ...\& Sathyakumar, S. (2020). Landscape predictors of human-leopard conflicts within multi-use areas of the Himalayan region. Scientific reports, 10(1), 1-12.

Nowell, K., \& Jackson, P. (Eds.). (1996). Wild cats: status survey and conservation action plan (Vol. 382). Gland, Switzerland: IUCN.

Ott, T., Kerley, G. I., \& Boshoff, A. F. (2007). Preliminary observations on the diet of leopards
(Panthera pardus) from a conservation area and adjacent rangelands in the Baviaanskloof region, South Africa. African Zoology, 42(1), 31-37.

Owen-Smith, N., \& Mills, M. G. (2008). Predatorprey size relationships in an African large-mammal food web. Journal of Animal Ecology, 77(1), 173-183.

Peters, G. (1982). Zurfellefarbe und-zeichnungeinigerfelichen (Mammalia, carnivore).

Pianka, E. R. (1974). Evolutionary Ecology Harper and Row New York. Pianka Evolutionary Ecology 1974.

Pocock, R. I. (1917). XL.-The classification of existing Felidæ. Annals and Magazine of Natural History, 20(119), 329-350.

Quinn, J. L., \& Cresswell, W. (2004). Predator hunting behaviour and prey vulnerability. Journal of Animal Ecology, 73(1), 143-154.

Rostro-García, S., Kamler, J. F., Crouthers, R., Sopheak, K., Prum, S., In, V., ...\& Macdonald, D. W. (2018). An adaptable but threatened big cat: density, diet and prey selection of the Indochinese leopard (Panthera pardus delacouri) in eastern Cambodia. Royal Society open science, 5(2), 171187.

Sharma, H. P., Adhikari, B., Bhandari, S., Baral, K., \& Kunwar, R. M. (2021). Crab-Eating Mongoose Herpestes urva: Occurrence and its Activity in Mid-Hills of Nepal. Journal of Institute of Science and Technology, 26(2), 53-60.

Shehzad, W., Nawaz, M. A., Pompanon, F., Coissac, E., Riaz, T., Shah, S. A., \&Taberlet, P. (2015). Forest without prey: livestock sustain a leopard Panthera pardus population in Pakistan. Oryx, 49(2), 248-253.

Sunquist M.E., Sunquist F.C. (1989) Ecological Constraints on Predation by Large Felids. In: Gittleman J.L. (eds) Carnivore Behavior, Ecology, and Evolution. Springer, Boston, MA.

Van Cleave, E. K., Bidner, L. R., Ford, A. T., Caillaud, D., Wilmers, C. C., \& Isbell, L. A. (2018). Diel patterns of movement activity and habitat use by leopards (Panthera pardus pardus) living in a human-dominated landscape in central Kenya. Biological Conservation, 226, 224-237.

Wang, S. W., \& Macdonald, D. W. (2009). The use of camera traps for estimating tiger and leopard populations in the high altitude mountains of Bhutan. Biological Conservation, 142(3), 606613. 